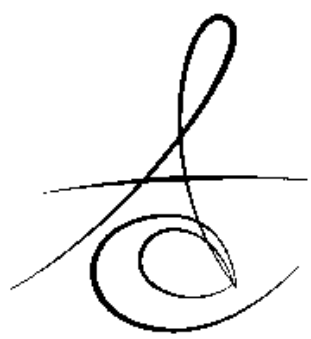

\title{
ORTODONTİDE BRAKET SÖKÜMÜ YAPILIRKEN DİKKAT EDİLMESİ GEREKENLER
}

\author{
CONSIDERATIONS IN ORTHODONTIC DEBONDING
}

Dt. Erhan GÖRÜKMEZ*

Yrd. Doç. Dr. Sertaç AKSAKALLI*

Makale Kodu/Article code: 2346

Makale Gönderilme tarihi: 06.07.2015

Kabul Tarihi: 06.01.2016

öz

Ortodontide braket sökümü sabit ortodontik tedavi sonunda braketlerin ve yapıştırıcı simanın diş yüzeyinden uzaklaştırılma işlemidir. Ortodontide braket sökümü işlemi braketlerin ve diğer ortodontik ataşmanların sökülmesi, diş yüzeyinin temizlenmesi ve cilalanması olmak üzere iki aşamadan oluşmaktadır. Braket ve diğer ortodontik ataşmanların sökülmesi için birçok yöntem mevcuttur.

Ortodontide braket sökümü işlemi sırasında uygulanan kuvvete bağlı olarak pulpa dokusunda bazı değişiklikler meydana gelmektedir. Uygun olmayan kuvvet ve ortodontide braket sökümü yöntemi minede ve pulpada hasarlara neden olmaktadır.

$\mathrm{Bu}$ çalışmada farklı braket sistemlerine uygulanan ortodontide braket söküm yöntemleri tartışılmış ve dental etkileri incelenmiştir.

Anahtar kelimeler: Braket sökümü; ortodonti

\section{GİRIŞ}

Ortodonti tedavisinin ideal bir şekilde bitirilmesinde, tedavinin başından sonuna kadar dikkat edilmesi gereken birçok faktör vardır. Yapıştııılan ataşmanların sökülmesi ve geriye kalan siman artıklarının temizlenmesi de bunlardan bir tanesidir. Diş ve çevre dokulara zarar vermeden yapılması gererken iyi bir ortodontide braket sökümü işlemi birçok faktöre bağlıdır. Bunlardan en önemlileri kullanılan yapıştırıcının dişle bağlanma şekli, oluşturduğu bağlanma kuvveti, sabit ataşmanların diş yüzeyinden kopartılması ve mine yüzeyinde kalan artık yapıştırıcıyı temizleme yöntemidir. ${ }^{1-3}$

Sabit ataşmanların, tedavi süresince hekim tarafından uygulanan mekanik kuvvetlere, çiğneme ve

\section{ABSTRACT}

Debonding is a technique which is used at the end of the fixed orthodontic treatment for removal of the bracket and adhesive resin from the tooth surface. Debonding process consists of two stages. These stages are; removing brackets and other orthodontic attachments and cleaning and polishing of the tooth surface. There are several methods for removing brackets and other orthodontic attachments.

Depending on the force applied during debonding, some changes occur in pulp tissue. Improper force and debonding methods cause damages to the enamel and pulp tissue.

In this study, debonding methods applied to different bracket systems have been discussed and dental effects were examined.

Keywords: Debonding, orthodontic

parafonksiyonlar sırasında oluşan kuvvetlere ve hastaların kötü kullanım kuvvetlerine direnç göstermesi istenir. Ancak istenen bu direnç braketlerin sökümü aşamasında minenin koheziv iç gücü olan yaklaşık 14 MPa'ı geçmemelidir. Aksi durumda minenin bütünlüğü bozulabilir. 45

Braket sökümü işlemi esnasında 3 ara yüzden birinde meydana gelen kırılma sayesinde braketler diş yüzeyinden uzaklaştırılmaktadır. Bu kırılma alanları yapıştırıcı siman ile braket arasında (koheziv kırılma), yapıştırıcı simanın kendi içerisinde ve diş yüzeyi ile yapıştırıcı siman arasında (adeziv kırılma) oluşmaktadır.

Koheziv kırılma adeziv kırılmaya göre daha güvenli olmaktadır. Ancak büyük ölçüde söküm yöntemine ve braket materyaline bağlı olan adeziv kırılmada, diş yüzeyinde daha az artık madde kalmakta ve

* Bezmialem Vakıf Üniversitesi Diş Hekimliği Fakültesi Ortodonti AD. 
temizleme işlemi daha kısa sürede tamamlanmaktadır. ${ }^{6,7}$ Fakat diş yüzeyi ile yapıştıııı siman arasındaki bu kırılma minenin yüzey özelliklerini bozabilir.

\section{YAPIŞTIRMA AŞAMASINDA ÖNEMLİ NOKTALAR}

Ortodontide uygulanan sabit tedavi tekniklerinde kullanılan ataşmanların direkt olarak dişe yapıştırıması ve diş üzerindeki retansiyonunun ve sağlamlığının güçlü olması tedavinin başarısını doğrudan etkileyen bir husus olup ortodontist tarafından üzerinde önemle durulması gereken konulardan birisidir. Ortodontik ataşmanların mine dokusuna bağlanma kuvvetini, mine yüzeyinin fizyolojik özellikleri ve kristal yapısı, diş üzerinde bulunan bakteriyel plağın varlı̆ı ve periodontal dokuların sağlığı, salivasyon miktarı ve engellenebilir olmasının yanı sıra;

- Mineye uygulanan asidin tipi, konsantrasyonu ve uygulama süresi,

- Mineye uygulanan yapıştıııının yapısı,

- Braket materyali ve kaide yapısı,

- Polimerizasyon için kullanılan ışık cihazının cinsi, uygulama süresi,

- Polimerizasyon öncesi uygulanan profilaktik antibakteriyel ajanlar,

gibi faktörler de etkilemektedir. ${ }^{89}$

Kendinden asitli sistemlerin uygulama süresi açוsından kolay olmasına karşın, geleneksel yöntemlere göre daha zayıf mine bağlantısı oluşturdukları görülmüştür. Aynı zamanda nem hassasiyetlerinin daha fazla olduklarından dolayı, tükürük kontaminasyonunun yapıştırma uygulamasında başarısızlığa neden olmaktadır. ${ }^{10}$

İyi bir yapıştııııdan beklenen özellikler; braket ile diş bağlantısını güçlü bir şekilde sağlaması, nemden etkilenmemesi, braket sökümü sonrasında mine yüzeyine zarar vermeden en kolay şekilde uzaklaştırılmalıır. Özellikle kötü oral hijyene sahip bireylerde tedavi sırasında oluşan streptecoccus mutans seviyesindeki artışa bağlı olarak ortaya çıkan demineralizasyonu ve beyaz nokta lezyonlarının azaltılmasında etkili olmalıdır. Farkı antimikrobiyal ajanların yapıştııııılara eklenmesi laboratuvar ortamında olumlu sonuçları olmasına karşın, bu yapıştıııııarın geliştirilmesi için klinik çalışmalarda gerekmektedir. ${ }^{11}$

Son yıllarda ortaya çıkan nano kompozit yapıştırıcıların kullanııması yeterli yapışma gücü elde etmenin yanı sıra braket sökümü esnasında daha az mine hasarı oluşturduğu söylenmiştir. ${ }^{12}$
Porselen üzerine braketlerin yapıştıııması sırasında seramiğin yüzey özelliklerinin değiştirilebilmesi için çeşitli mekanik ve kimyasal yöntemler kullanılmaktadır. Porselen yüzeyinin mekanik olarak değiştirilmesi porselenin glaze tabakasının kaldırıması ve yüzeyin pürüzlendirilmesi ile olmaktadır. Kumlama yada elmas frezler kullanılarak bu işlem gerçekleştirilebilmektedir. Bu yöntemlerde porselen üzerine geri dönüşümsüz hasar oluşur ve braket sökümü esnasında porselen yüzeyde kırılmalar meydana gelebilmektedir. ${ }^{13-16}$

Aksakallı ve ark. ${ }^{17}$ yapmış olduğu, porselen laminaya yapıştırımış braketlerin bağlanma gücünün farklı yüzey pürüzlendirme yapılarak karşılaştırıldığı bir çalışmada; makaslama kuvvetlerine karşı en yüksek dayanıklığı hidroflorik asit ile pürüzlendirmede görülürken kumlama yöntemi ideal bir bağlanma değeri ortaya koyamamışır. Laminadaki yüzey hasarı açısından tüm gruplarda anlamlı bir farklıık gözlemlenmemiş fakat Er.YAG lazer uygulaması ideal bağlantı ve lamina yüzeylerinde minimum hasar oluşturmasından dolayı seçilebileceğini söylemişlerdir.

Farklı yapışııııı ve pürüzlendirme yöntemi ile yapılan çalışmada yapışırma sonrası mikrosızıntı skorlarının yapıştıııının tipine göre farklılık göstermediği, fakat mine ile yapışıııı ırasındaki sızıntının yapıştıııı ile braket arasındakinden daha fazla olduğu bulunmuştur. ${ }^{18}$ Mikrosızıntı minede dekalsifikasyon ve beyaz nokta lezyonlara neden olabilmektedir. ${ }^{19}$

Aktif tedavinin bitirilmesi safhası genel olarak braketlerin ve diğer ortodontik ataşmanların sökülmesi, diş yüzeyinin temizlenmesi ve cilalanması olarak 2 kısma ayrımaktadır.

\section{BRAKETLERİN VE DİĞER ORTODONTİK ATAÇMANLARIN SÖKÜLMESİ}

Braketlerde meydana gelen deformasyonun önlenmesi ve mine yüzeyine gelen travmanın azaltıla- bilmesi amacıyla literatürde farklı braket söküm teknikleri bildirilmiştir. Ayrıca farklı materyallerden üretilmiş braketler için de alternatif sökümü teknikleri bulunmaktadır.

\section{Mekanik söküm}

Mekanik braket sökümü yönteminde amaç brakete penslerle kuvvet uygulayarak braket-yapıştırıı siman ara yüzeyindeki mekanik bağlantıyı koparmaktır. ${ }^{20}$ 


\section{Metal braketlerin mekanik olarak sökülmesi}

Yapıştırıcı simanlar ile yapıştırımış metal braketler için genellikle mekanik söküm yöntemleri tercih edilmektedir. Metal braketlerin sökülmesinde en güvenir yol braket tabanı ile yapıştırıcı siman arasında kırılma yapmaktır. Bu şekilde kuvvet uygulanması metal braketlerde kalıcı deformasyonlara neden olabilmektedir. 6

Metal braketlerin mekanik olarak sökülmesinde 3 yöntem kullanılmaktadır. ${ }^{6}$

1. yöntem: Bu yöntemde weingart ya da howe pensi gibi yardımcı pensler kullanılır ve braket kanatları mesio-distal yönde sıkıştırılıp braketin diş yüzeyinden ayrılması sağlanır (Resim 1). Bu yöntemde yapıştırıcın büyük bir kısmı diş yüzeyinde kalmaktadır. ${ }^{21}$

2.yöntem: Bu yöntemde keskin uçlu braket söküm pensleri kullanılmaktadır (Resim 2). Bu pensler ile mine-yapıştırıcı siman ya da braket-yapıştııı siman ara yüzünde makaslama kuvveti meydana gelmektedir. Bu yöntemde diş üzerinde kalan yapıştırıcı miktarı minimum seviyededir. Direkt yapıştırma yöntemiyle yapıştırılan braketler bu teknik ile söküldüğünde minede hasar oluşma intimali fazla olmaktadır. ${ }^{21}$

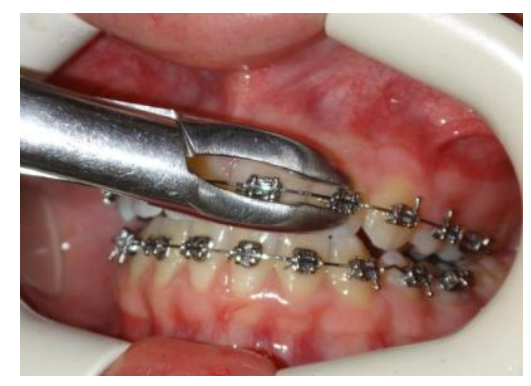

Resim 1 . Weingart pensi ile braket sökümü.

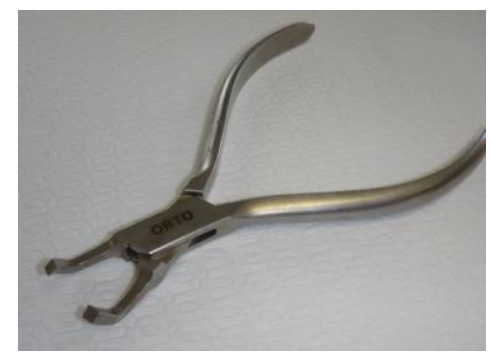

Resim 2 . Braket sökümünde kullanılan keskin uçlu söküm pensi.

3.yöntem: $\mathrm{Bu}$ yöntemde çekme kuvveti uygulayan özel olarak dizayn edilmiş pensler kullanılmaktadır. Bu yöntemde hemen hemen tüm yapıştırıcı, diş yüzeyinde kalmakta fakat braket deformasyonu daha az olmaktadır. ${ }^{21}$

\section{Seramik braketlerin mekanik olarak sökülmesi}

Kimyasal ya da mekanik tutuculuğa sahip seramik braketlerin mekanik olarak sökülmesinde farklı yöntemler bildirilmiştir. ${ }^{22,23}$ Her üretici firma kendi braketi için özel el aleti veya pens geliştirmiştir. Her braket için özel olarak tarif edilen söküm yönteminin kullanılması tavsiye edilmektedir. ${ }^{24} \mathrm{Bu}$ pensler ya braketi deforme ederek braket-yapıştırıcı siman ara yüzeyinde kırılmaya yol açar veya yapıştırıcı siman içinde stres oluşturarak kompozit siman içerisinde koheziv kırılmaya neden olur. Araştırmacılar mine-yapıştırıcı ara yüzüne yerleştirilen keskin uçlu pensler yardımıyla uygulanan çift taraflı kuvvetin polikristalin ve monokristalin braketlerin sökülmesinde kullanılabilecek en etkili yöntem olduğunu bildirmişlerdir. ${ }^{22} 23$

Seramik braketin tabanına yerleştirilen vertikal slot söküm işlemini kolaylaştırmaktadır. ${ }^{25} \mathrm{Bu}$ oluğun bir kırılma noktası oluşturarak braketlerin mineye zarar vermeden sökülmesini sağladığı bildirilmiştir. ${ }^{26} \mathrm{Bu}$ yöntemde ortodontik sökümde kullanılacak pens meziodistal yönde yerleştirilmekte ve braketin vertikal oluk üzerinde katlanması prensibi ile braket sökümü yapılmaktadır.

Seramik braketlerin indirekt yapıştırma tekniği ile yapıştırımasının braket sökümü prosedürünü kolaylaştırdığı bildirilmiştir. ${ }^{22} 23$

\section{Elektrotermal söküm yöntemi}

Metal ortodontik braketlerin klasik söküm yöntemleriyle tedavi sonrası diş yüzeyinden uzaklaştırılmasına alternatif olarak geliştirilmiştir. Elektrotermal söküm yöntemi şarj edilebilir, kablosuz aletlerle brakete ISI verilirken bir yandan da sökücü kuvvet uygulanması prensibine dayanır. ${ }^{27}$ Elektrotermal sökümde ISI uygulayan uç vertikal slota yerleştirilir ve hafif bir torsiyonel kuvvet ile braketi diş yüzeyinden ayırır.

Metal brakete 200-250 Co civarında ISı uygulandığında bu ısı braket/yapıştırıcı siman ara yüzeyine transfer olup yapıştırıcı simanı yumuşatarak deforme etmektedir. ${ }^{27}$ Böylece braket klasik yöntemlerde olduğu gibi aşırı bir kuvvet yüklemesi olmadan diş yüzeyinden uzaklaştırılmaktadır.

Yöntem oldukça hızlı, etkili ve braket veya

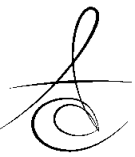


minede kırılmalara yol açmaması açısından güvenlidir. ${ }^{28}$ En önemli avantajları arasında dişe aşırı kuvvetler uygulamayı engelleyerek mineyi korumasıdır. Hasta açısından daha rahat olması ve özellikle metal braketlerin deforme olmasını önlediği için braketlerin yeniden kullanılabilmesine izin vermektedir. ${ }^{27,28}$ En önemli dezavantajı ise oluşan yüksek ısının pulpa dokusunda hasar oluşturma riskidir. Bu yöntemde braketin diş yüzeyinden uzaklaştırılmasından sonra yapıştırıcı simanın tamamının diş yüzeyinde kalması ve bu artık simanin diş yüzeyinden temizlenmesi klinisyen açısından zaman kaybı olarak algılanmaktadır. ${ }^{20}$ Diğer dezavantajları ise ıSı uygulayan aletin büyüklüğü nedeniyle özellikle küçük azı bölgesinde uygulama zorluğu ve ısınmış braketin hasta ağzına düşme riskidir. ${ }^{28}$

\section{Ultrasonik söküm yöntemi}

Ultrasonik teknikte mine ve braket tabanı arasındaki yapıştırıcıyı aşındırmak için braket-yapıştırıcı ara yüzeyine uygulanan özel olarak tasarlanmış uçlar kullanılmaktadır. ${ }^{29}$ Ultrasonik yöntemde braketin çıkarılması için gereken kuvvet büyüklüğü geleneksel yöntemden çok daha azdır. Ayrıca bu teknik, mine hasarı veya braket kırıması olasılığını azaltmakta ve braket çıktıktan sonra kalan yapıştırıcı da kullanılan uçla temizlenebilmektedir. Ancak her bir braketin çıkarılma süresi 30-60 saniye arasında olduğu için ultrasonik söküm yöntemi çok zaman alıcıdır. Ayrıca oldukça pahalı olan ultrasonik uçta zamanla aşınma meydana gelir. Bu aşınma daha yumuşak olan çelik ucun sert olan seramik üzerinde hareketi ile oluşan sürtünmeden kaynaklamaktadır. ${ }^{30}$ Pulpa dokusunda oluşabilecek zararı en aza indirmek için su spreyi ile ısının kontrol altında tutulması gerekliliği de bu tekniğin bir diğer dezavantajıdır. Ultrasonik söküm seramik braketlerin çıkarılmasında klinik bir yöntem olarak henüz önerilmemektedir. ${ }^{31}$

\section{Lazer ile söküm yöntemi}

Lazer uygulaması (Resim 3) genel olarak elektrotermal yaklaşıma benzer şekilde ısı oluşturarak yapıştırıcının yumuşatılması ve büzülmesi prensibine dayanır. ${ }^{32}$ Seramik braketlerin sökülmesi için lazer kullanımı da araştırılmıştır. Seramik braketler üzerine Er-YAG lazer etkileri;

1-Lazer destekli söküm seramik braketlerin minede kopma veya braket fraktürü meydana gelmeden sökülmesini sağlar.

2-ER-YAG lazer kullanımı ARI(adhesive remnant index) skorunu yükseltir ve minede meydana gelebilecek kırık riskini azaltır.

3-ER-YAG lazer polikristalin seramik braketlerin yapışma dayanıkılığını azaltmada etkilidir

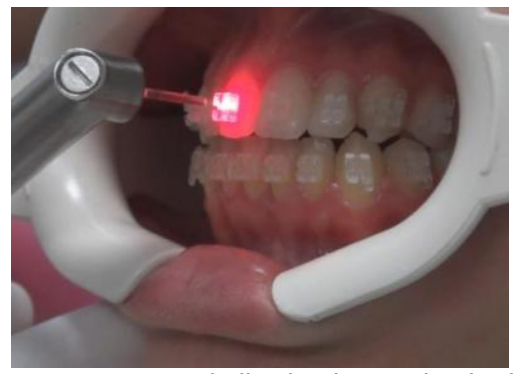

Resim 3 . Lazer kullanılarak porselen braketin sökülmesi.

Monokristalin ve polikristalin porselenler farklı dalga boylarındaki lazer ışı̆̆ına farklı reaksiyonlar vermektedirler. ${ }^{33}$ Polikristalin seramik braketlere $\mathrm{CO}^{2}$ lazerle $(14 \mathrm{~W}) 2$ saniye uygulama gerekli iken monokristalin seramik braketlerde bunun yarısı kadar bir enerji yeterli olmaktadır. Lazer uygulandıktan sonra geçen süre braketlerin sökülmesi için gerekli olan kuvveti artırdığı için braketlere tek tek lazer uygulanmalı ve hemen sonrasında braketler çıkarılmalıdır. Yapılan çalışmalar bis-GMA kullanıldığında lazerin yapıştırıcıyı braketle birlikte uzaklaştırdığını, metil metakrilat simanın ise diş yüzeyinde kaldığını ortaya koymuştur. Bu nedenle metil metakrilat siman kullanılması daha güvenlidir. ${ }^{34}$

Geleneksel yöntemle kıyaslandığında uygulanan kuvvet, mine hasarını ve braket kırılma riskini belirgin olarak azaltması nedeniyle avantajlıdır. Diğer bir avantajı da Seramik braketlerin sökümü için harcanan süre lazer kullanımı ile azaltılmıştır. Ayrıca hasta için daha az travmatik ve ağrı vericidir. Üretilen ISI kontrol edilebilmektedir. En önemli dezavantajları ise oluşturduğu ISı enerjisinin pulpa dokusu üzerindeki etkisi ve maliyetinin yüksek olmasıdır. Pulpada hasar oluşma riskini azaltmak için; süper-pulse $\mathrm{CO}^{2}$ lazer (2W) güçte 4 saniyeden $\mathrm{az}, \mathrm{CO}^{2}$ lazer $3 \mathrm{~W}$ güçte 3 saniye, normal $\mathrm{CO}^{2}$ lazer $18 \mathrm{~W}$ güçte 2 saniye süreyle kullanılmalıdır. ${ }^{34}$

\section{BRAKET SÖKÜMÜ SONRASI DİŞ YÜZEYİNİN TEMİZLENMESİ VE CİLA}

Literatürde braketlerin ve ortodontik ataşmanların sökülmesinden sonra, dişe zarar vermeden mine yüzeyinin yapı ve görüntü olarak orijinal haline getirilmesi ve yüzey pürüzsüzlüğünün sağlanması için pek çok yöntem geliştirilmiştir. ${ }^{35} 36$ Bantların sökülmesinden sonra kalan siman küretler ile rahatlıkla 
temizlenebilmesine rağmen dişlerin üzerinde kalan yapışıııcı simanın temizlenmesi daha komplikedir.

Braketlerin sökülmesinden sonra kullanılacak yöntemler tek basamaklı ya da çok basamaklı olarak yapılabilir.

\section{Tek aşamalı sistemler}

Tek basamakı işlemler elmas kapılı lastik frezler (Resim 4) ve silikon karbit fırçaların kullanımından oluşmaktadır.

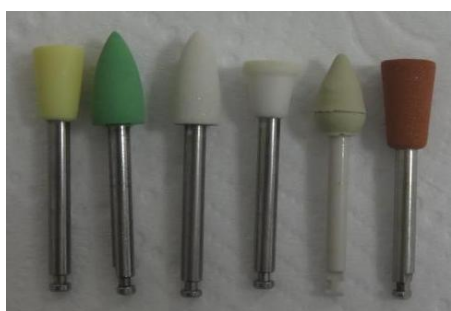

Resim 4 . Farklı tip elmas kaplı lastik frezler.

Ortodontide braket sökümü sonrası artık simanın temizlenmesi için el aletleri, zımpara diskler, yeşil lastik frezler ve tungsten karbit frezler gibi çok sayıda temizleme yöntemi kullanılmaktadır. Bazı araştırmacılar braket sökümü işlemi sonrasında konvansiyonel elmas frezlerin kullanımını önermesine rağmen bazı araştırmacılar da mine yüzeyinde derin oluklar oluşturdukları için bu frezlerin kesinlikle kullanılmaması gerektiğini bildirmişlerdir. ${ }^{37}$ Elmas frezler hızlı bir şekilde artık simanı temizlerken diş dokusunda da madde kaybına neden olmaktadırlar. Söküm sonrası diş yüzeyinde kalan kompozit simanın temizlenmesinde en iyi yöntemin tungsten karbit frez kullanılarak (Resim 5) yapılan temizleme yöntemi olduğu bildirilmiştir. ${ }^{38}$ Elmas frezlere göre daha uzun süren bu işlem daha kontrollü olmaktadır.

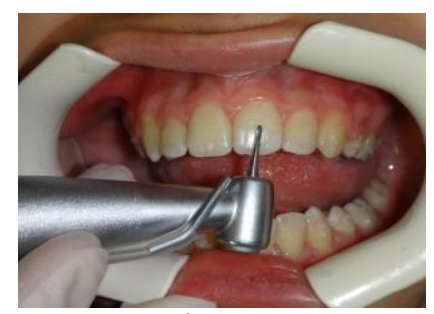

Resim 5 . Artık yapıştııııının tungsten karbit frez ile uzaklaştırılması.

Konvansiyonel olarak kullanılan tungsten karbit frezler çeşitli boyutlarda ve şekillerde bulunmaktadır. 12 ve 30 yivli olanların mine için daha güvenli olduğu bildirilmiştir. Yüksek doldurucu içeren simanlarin temizlenmesi için en etkili yöntemin 30 yivli tungsten karbitfrez kullanımı olduğunu belirtilmiştir. ${ }^{35}$ Ayrıca diş yüzeyinden artık simanin temizlenmesinin en çabuk 30 yivli tungsten karbit frezler ile yapıldığı bildirilmiştir. ${ }^{39}$ Zachrisson ve Artun $^{38}$ düşük hızda tungsten karbit frez kullanımını önerirken, Campbell ${ }^{35}$ ve Rouleau ${ }^{36}$ yüksek hızda su soğutması altında bu frezlerin kullanımını tavsiye etmişlerdir. Retief ve Denys ${ }^{37}$ ise diş yüzeyinde kalan artıkları daha rahat görebilmek için hava ile soğutmanın yeterli olacağını bildirmişlerdir. Su soğutması olmadan gerçekleştirilen tekniklerin su soğutması ile yapılanlara göre pulpada daha fazla ISI oluşumuna neden olduğu bildirilmiştir. ${ }^{40}$ Artık simanın temizlenmesi esnasında minenin korunması kadar pulpanın da aşııı ısıdan koruması gerekmektedir.

Koh ve ark. ${ }^{41}$ yüzey pürüzlülüğünün cilalamada kullanılan aletin özellikleriyle ilgili olduğunu belirtmişlerdir. Farklı bitirme sistemlerinin karşılaştırıldığı bir çalışmada Po-Go mikro parlatıcıların en iyi sistem olduğu ve bunu da Super-Snap Rainbow sisteminin takip ettiği bildirilmiştir. ${ }^{39}$ Elektron mikroskobu görüntülerine göre orijinal mine yüzeyine en yakın sonucu po-go parlatıcıları vermektedir. Ancak bu sistem uzun uygulama süresi gibi bir dezavantajı bulunmaktadır.

Ayrıca $\mathrm{CO}^{2}$ ve Nd:YAG laser, air-powder abraziv sistemler de artık simanın diş yüzeyinden uzaklaştırılmasında kullanılmaktadır. ${ }^{42}{ }^{43}$ Ancak lazer sistemlerin her klinikte olmayışı, pahalı olmaları ve hastayla geçirilen zamanın artması gibi dezavantajlarının olmasından dolayı yaygın kullanımı olmayabilir. Air-powder abrazivler maliyet olarak avantajlı olsalar da, uygulanan bölgede izolasyonun yapılması, uzun uygulama süreleri dezavantajlarıdır. Günümüz ortodontisinde ortaya çıkan tekniklerin yaygınlaşmasında uygulama süresi ve maliyet boyutu avantajlarını da içeren uygulamalar diğerlerine nazaran daha ön plana çıkmaktadır.

Porselenin yüzey pürüzlülüğünü yok etmek amacıyla çeşitli bitim ve cilalama teknikleri bildirilmiştir. Elmas frezler ve lastik abrazivler gibi döner sistemler ile klinik olarak kabul edilebilir bir pürüzsüzlük elde edilebilmektedir. Söküm sonrası 3 farklı porselen tipinin yüzey pürüzlülüğünün giderilmesi için kullanılan 2 yöntemin karşılaştııılığı çalışmada Sof-Lex disklerin porselen cila lastiği ve cilalama patına göre daha pürüzsüz bir yüzey oluşturduğu bildirilmiştir. ${ }^{44}$

Ultrasonik titreşimlerde artık yapıştıııının uzakIaştırımasını sağlar. Ultrasonik titreşimler ses dalga-

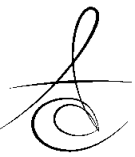


larıyla aynı tipte ancak frekansları daha fazla olan mekanik titreşimlerdir. Titreşim hareketinin en ileri ve en geri noktası arasındaki mesafe 0.006-0.1 mm. arasında değişmektedir. Ucun bir saniyedeki titreşim sayısı ise 25.000-42.000 arasında değişir. Braketlerde herhangi bir kırık oluşturmadan dişten ayrılması sağlanmasına karşın, fazla zaman alması, ISI ve pulpal hassasiyeti önlemek için kullanılan su spreyinin dişlerde oluşturduğu ağrı ve diş yüzeyinde derin çizikler oluşturma intimali dezavantajlarıdır. Yapılan bir çalışmada, yüksek hızı ve düşük hızlı tungsten karbit frez, ultrasonik kazıyıcı ve braket söküm pensi karşılaştırılmıştır. En fazla mine yüzeyi kaybının ultrasonik kazıyıcı ve yüksek hızı tungsten karbit frezde meydana gelmiştir. ${ }^{45}$ Ultrasonik söküm yönteminin etkilerinin incelendiği ve bu yöntemin frez ve cila disklerinin kullanıldığı geleneksel söküm yöntemiyle karşılaştırıldığı başka bir çalışmada ise bu yöntemin kullanılması ile mine de oluşan kaybın azaltıldığı söylenmiştir. ${ }^{13}$

\section{Çok aşamalı sistemler}

Sof-Lex, Super-Snap gibi alüminyum oksit ile kaplı disklerin kullanımını içeren çoklu sistemler son zamanlarda popülarite kazanmıştır. Bu sistemlerde kalın grenli frezlerden başlayarak kademeli olarak ince grenli frezlere geçilmektedir. Bu sistemlerin en önemli dezavantajı zaman alıcı olmalarıdır. Hasta başında geçirilen süreyi kısaltmak için Po-Go, Opti-Shine gibi elmas ya da silikon kaplı parlatıcılar piyasaya sürülmüştür.

Sacha ve ark. ${ }^{46}$ yapmış olduğu bir çalışmada tungsten karbit frezle kombine edilmiş farklı bitim lastiklerinin mine yüzeyine olan etkilerini incelemiş ve karbit frezler ile temizleme prosedürlerinin çok fazla diş dokusu kaybı ile sonuçlandığını ve mine yüzeyinde fazla miktarda kompozit miktarı gözlemlendiğini ve mine kaybını önlemede çok basamaklı kauçuk cilalama setlerinin avantajlı olduğu söylemişlerdir. Ayrıca iyi bir kompozit cilalama özelliklerine sahip cilalama sistemlerinin parlak bir yüzey oluşturabileceğini böylelikle daha fazla kompozitin görünmez hale gelebileceğini, çünkü farklı temizleme metotlarının yüzey değişimleri üzerinde önemli bir etkiye sahip olmadığını fakat mine kaybı olmaksızın yeterli bir temizlemenin başarılması zor bir durum olduğunu belirtmişlerdir. Çünkü yapılan pürüzlendirmeyle birlikte yapıştırma ajanlarının mine prizmalarına invaze olmaları ve braket söküm sonrası mikron boyutundaki uzantıların temizlenmelerini zorlaştırmaktadırlar.
Braketlerin sökümünden sonra farklı cilalama sürelerinin değerlendirildiği bir çalışmada söküm işlemi sonrasında pomzalamanın mutlaka gerekli olduğu ve cilalama süresinin arttırılarak çevre mine dokusuna yakın yüzey elde edilebildiği bildirilmiştir. ${ }^{47}$ Braket söküm sonrası yüzey pürüzlüğünün elimine edilebilmesi için fiberglas frezler ile Sof-Lex disklerin karşılaştırıldığı çalışmada Sof-Lex disklerin yüzey pürüzlülüğünün giderilmesinde oldukça başarılı olduğu bulunmuştur. ${ }^{48}$

\section{BRAKET SÖKÜMÜNÜN DİŞLER ÜZERİNDEKİ ETKİLERİ}

Uygun olmayan söküm teknikleri minede ciddi hasarlara neden olmaktadır. Braketlerin sökülmesi sırasında ve bitim, cilalama işlemlerinin yetersiz yapılması sonucunda estetik problemler, diş hassasiyeti, artmış çürük riski, pulpa nekrozu, mine yüzeyinde çatlak, mine prizmalarında kırılmalar diş yüzeyinde aşırı plak birikimi, dişeti iritasyonu ve diş yüzeyinde renklenme meydana gelmektedir. ${ }^{39,49,50}$

Braketlerin sökülmesi, artık yapıştırıcının temizlenmesi ve bitim işlemlerinden sonra diş yüzeyinde meydana gelen değişiklikler 3 boyutlu lazer taraması ile incelenmiştir. Bu araştırmaya göre yapıştırma işleminin nemli koşullarda yapılmasının braket sökümü işlemi sonrasında mine yüzeyinde kalan yapıştırıcı miktarını çok azalttığı ya da tamamen ortadan kaldırdığı bildirilmiştir. $^{51}$ Yapılan araştırmalarda farklı bitirme tekniklerinin 22-50 mikrometre kadar minede kayıp meydana getirdiği, fakat tungsten karbit frez ile düşük hızda daha kontrollü kullanımı ve kademeli bitim lastiklerinin kullanımı ile bu kaybın 2.9 mikrometreye kadar düşebileceği görülmüştür. ${ }^{1}$

Pratikte amaç, braket söküm sonrası mine görünümünün, ıslak ve kuru olarak komşu doğal mine yüzeyiyle benzer olmasıdır. Kuru görünümün değerlendirilmesi önemlidir çünkü ıslak yüzeyle bağlantılı olan kırılma ve yansıma fenomeni yüzey düzensizliklerini maskeleyebilir.

Literatürde akışkan kompozitler ile yapıştırılan braketlerin sökülmesinden sonra mine üzerinde oluşan değişiklikler geleneksel kompozitler ile karşılaştırılmış ve çatlak, kırık gibi mine hasarları oluşturma açısından akışkan kompozitler ile geleneksel kompozitler arasında fark bulunmamıştır. ${ }^{52}$

Mine hasarı metal braketlere oranla seramik braketlerde daha fazla görülmektedir ve monokristalin

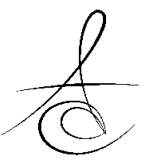


seramik braketler polikristalin braketlerden daha fazla mine kaybı oluştururlar. Ayrıca kimyasal tutunan braketler mekanik tutunanlara göre daha fazla mine hasarına yol açarlar. ${ }^{34}$

Diş yapısının bütünlüğü gelişimsel defekt, mine çatlağı veya geniş restorasyon gibi nedenlerle önceden bozulmuşsa ya da seramik braket canlı olmayan bir dişe yapıştırımışsa mekanik ortodontide braket sökümüile hasar oluşma olasılığı daha yüksektir. 3051 Bu nedenle bu tür durumlarda seramik braket kullanmaktan mümkün olduğu kadar kaçınılmalıdır.

SONUÇ

Ortodontide braket söküm prosedürü ile ilgili uluslararası kabul edilen bir prosedür bulunmadığı için hekim güncel bilgi ve klinik tecrübeler doğrultusunda hastada en az hasar oluşturacak şekilde tedaviyi bitirmelidir. İdeal laboratuvar koşullarında oldukça etkili olan geleneksel mekanik söküm tekniklerinin kullanılması düşünülüyorsa dişin yapısal özelliği mutlaka göz önüne alınmalıdır. Seramik braketlerin sökülmesi esnasında dikkatli olunmalı ve üretici firmanın talimatları takip edilmelidir

\section{KAYNAKLAR}

1. Al Shamsi, A.H., Cunningham, JL., Lamey, P.J, Lynch, E. Three-Dimensional Measurement of Residual Adhesive and Enamel Loss on Teeth After Debonding of Orthodontic Brackets: an In-Vitro Study, Am J Orthod Dentofacial Orthop 2007; 131: 9-301.

2. Hosein, I., Sherriff, M.,Ireland, A.J. Enamel Loss During Bonding, Debonding, and Cleanup with Use of a Self-Etching Primer, Am J Orthod Dentofacial Orthop 2004; 126:717-24.

3. Ireland, A.J, Hosein, I., Sherriff, M. Enamel Loss at Bond-Up, Debond and Clean-Up Following the Use of a Conventional Light-Cured Composite and a Resin-Modifiedglass Polyalkenoate Cement Eur J Orthod 2005; 27:413-9.

4. Katona, T.R. A Comparison of the Stresses Developed in Tension, Shear/Peel Testing of Direct Bonded Orthodontic Brackets-A Finite Element Model, Am J Orthod Dentofacial Orthop 1997; 112:244-51.

5. Katona, T.R. Stresses Developed During Clinical Debonding of Stainless Steel Orthodontic Brackets. Angle Orthod 1997; 67:39-46.
6. Bishara SE, VonWald L, Laffoon JF, Warren JJ Effect of a self-etch primer/adhesive on shear bond strength of orthodontic brackets. Am J Orthod Dentofacial Orthop 2001; 119:621-4.

7. Bishara SE, Gordon VV, VonWald L, Jacobsen JR. Shear bond strength of composite, glass ionomer, and acidic primer adhesive sytems. Am J Orthod Dentofacial Orthop 1999; 115:24-8.

8. Sunna S, Rock WP. Clinical performance of orthodontic brackets and adhesive systems: A randomized clinical trial. $\mathrm{Br}$ J Orthod 1998; 25:2837.

9. Whittaker DK. Structural variations in the surface zone of human tooth enamel observed by scanning electron microscopy. Arch Oral Biol 1982; 27:38392.

10. Atik $E$, Ciğer S. Comprasion of self-etch and conventional acid-etch techniques in orthodontic bonding process. J Dent Fac Ataturk Uni 2014; 24(3):452-57.

11. Kan H, Aydınatay BS, Ciğer S. Antibacterial adhesives in orthodontics. J Dent Fac Ataturk Uni 2013; 23(1):131-37.

12. T. Hosseinzadeh-Nik, A. Karimzadeh, M.R. Ayatollahi. Bond strength of a nano-composite used for bonding ceramic orthodontic brackets. Materials \& Design 2013; 51:902-6.

13. Gillis I, Redlich M. The effect of different porcelain conditioning techniques on shear bond strength of stainless steel brackets. Am J Orthod Dentofacial Orthop 1998; 114:387-92.

14. Andreasen GF, Stieg MA. Bonding and debonding brackets to porcelain and gold. Am J Orthod Dentofacial Orthop1988; 93:341-5.

15. Diaz-Arnold AM, Wistrom DW, Aquilino SA, Swift EJ Jr.Bond strengths of porcelain repair adhesive systems. Am J Dent 1993; 6:291-4.

16. Nebbe B, Stein E. Orthodontic brackets bonded to glazed and deglazed porcelain surfaces. Am J Orthod Dentofacial Orthop 1996; 109:431-36.

17. Aksakalli S, Ileri Z, Yavuz T, Malkoc M.A, Ozturk N. Porcelain laminate veneer conditioning for orthodontic bonding: SEM-EDX analysis. Lasers Med Sci 2015; 30(7):1829-34.

18. Alkis $\mathrm{H}$, Turkkahraman $\mathrm{H}$, Adanir N. Microleakage under orthodontic brackets bonded with different adhesive systems. Eur J Dent 2015; 9:117-21. 
19. Uysal T, Ramoglu SI, Ulker M, Ertas H. Effects of high-intensity curing lights on microleakage under orthodontic bands. Am J OrthodDentofacial Orthop 2010; 138:201-7.

20. Arıcı S, Türk T,Özer M. Metal braketlerde klasik ve elektrotermal debonding yöntemlerinin karşılaştırılması: Bir in vivo çalışma, Türk Ortodonti Dergisi 1999; 12(1):36-4.

21. Oliver RG. The effect of different methods of bracket removal on the amount of residual adhesive. Am J Orthod 1988; 93:196-4.

22. Sinha PK et al. Interlayer formation and its effect on debonding polycrystalline ceramic orthodontic brackets. Am J Orthod Dentofacial Orthop 1995; 108:455-8.

23. Sinha PK, Nanda RS. The effect of different bonding and debonding techniques on debonding ceramic orthodontic brackets. Am J Orthod Dentofacial Orthop 1997; 112:132-5.

24. Theodorakopoulou LP, Sadowsky PL, Jacobson A, Lacefield W. Evaluation of the debonding characteristics of 2 ceramic brackets: An in vitro study. Am J Orthod Dentofacial Orthop 2004; 125:329-36.

25. Bishara SE, Olsen ME, Von Wald L. Evaluation of debonding characteristics of a new collapsible ceramic bracket. Am J Orthod Dentofacial Orthop 1997; 112:552-9.

26. Liu JK, Chung $\mathrm{CH}$, Chang CY, Shieh DB. Bond strength and debonding characteristics of a new ceramic bracket. Am J Orthod Dentofacial Orthop 2005; 128:761-5.

27. Sheridan JJ, Brawley G, Hastings J Electrothermal debracketing. Part I. An in vitro study. Am J Orthod Dentofac Orthop 1989; 89:21-7.

28. Bishara SE, Trulove TS. Comparison of different debonding techniques for ceramic brackets: An in vitro study. Part II. Findings and clinical implications. Am J Orthod Dentofac Orthop 1990; 98:263-73.

29. Diaz-Arnold AM Schneider RC. , Aquilino SA. Bond strength of intraoral porcelain repair materials. J Prosthet Dent 1989; 61:305-9.

30. Bishara SE, Trulove TS. Comparison of different debonding techniques for ceramic brackets: An in vitro study. Part 1. Background and methods. Am J Orthod Dentofacial Orthop 1990; 98:145-53.
31. Daniel B. Boyer, Geoffrey Engelhardt, Samir E. Bishara Debonding orthodontic ceramic brackets by ultrasonic instrumentation. Am J Orthod Dentofac Orthop 1995; 108:262-66.

32. Strobl K, Bahns TL, Willham L, Bishara SE, Stwalley WC. Laser-aided debonding of orthodontic ceramic brackets. Am J Orthod Dentofac Orthop 1992; 101:152-8.

33. Eliades T, Johnston WM, Eliades G. Direct light transmittance through ceramic brackets. Am J Orthod Dentofac Orthop 1995; 107:11-9.

34. Azzeh E, Feldon PJ Laser debonding of ceramic brackets: A comprehensive review. Am J Orthod Dentofacial Orthop 2003; 123:79-83.

35. Campbell PM. Enamel surfaces after orthodontic bracket debonding. Angle Orthod 1995; 65:103-10.

36. Rouleau BD, Grayson WM, Cooley RO. Enamel surface evaluations after clinical treatment and removal of orthodontic brackets. Am J Orthod 1982; 81:423-6.

37. Retief DH, Denys FR. Finishing of enamel surface after debonding of orthodontic attachments. Angle Orthod 1979; 49:1-10.

38. Zachrisson BU, Artun J Enamel surface appearance after various debonding techniques. Am J Orthod 1979; 75:121-137.

39. Ulusoy Ç Comparison of finishing and polishing systems for residual resin removal after debonding. J Appl Oral Sci. 2009; 17(3):209-15.

40. Uysal T, Eldeniz AU, Usumez S, Usumez A. Thermal changes in the pulp chamber during different adhesive clean-up procedures. Angle Orthod 2005; 75(2):220-5.

41. Koh R, Neiva G, Dennison J, Yaman P. Finishing Systems on the Final Surface Roughness of Composites. J Contemp Dent Pract 2008; 138-45.

42. Smith SC, Walsh D, Taverne AA. Removal of orthodontic bonding resin residues by $\mathrm{CO} 2$ laser radiation: surface effects. J Clin Laser Med Surg 1999; 17:13-8.

43. Thomas BW, Hook CR, Draughn RA. Laser-aided degradation of composite resin. Angle Orthod 1996; 66:281-6.

44. Karan S, Toroglu MS. Porcelain Refinishing with Two Different Polishing Systems after Orthodontic Debonding. Angle Orthod 2008; 78:947-53. 
45. Hosein I, Sherriff M, Ireland AJ Enamel loss during bonding, debonding, and cleanup with use of a self-etching primer. Am J Orthod Dentofacial Orthop 2004; 126:717-24.

46. Ryf S, Flury S, Palaniappan S, Lussi A, Van Meerbeek B, Zimmerli B. Enamel loss and adhesive remnants following bracket removal and various clean-up procedures in vitro. Eur J Orthod 2012; 34:25-32.

47. Vieira AC, Pinto RA, Chevitarese O, Almeida MA Polishing after debracketing: its influence upon enamel surface. J Clin Pediatr Dent 1993; 18:7-11.

48. Ozer T, Başaran G, Kama JD. Surface roughness of the restored enamel after orthodontic treatment. Am J Orthod Dentofacial Orthop 2010; 137:36874.

49. Jefferies SR. The art and science of abrasive finishing and polishing in restorative dentistry. Dent Clin North Am 1998; 42:613-27.

50. Uçtasli $M B$, Arisu $H D$, Omürlü $H$, Eligüzeloölu $E$, Ozcan S, Ergun G.The effect of different finishing and polishing systems on the surface roughness of different composite restorative materials. J Contemp Dent Pract 2007; 8:89-96.

51. Joseph VP, Rossouw PE. The shear bond strengths of stainless steel and ceramic brackets used with chemically and light-activated composite resins. Am J Orthod Dentofacial Orthop 1990; 97:121-5.

52. Tecco S, Tetè S, D'Attilio M, Festa F. Enamel surface after debracketing of orthodontic brackets bonded with flowable orthodontic composite. A comparison with a traditional orthodontic composite resin. Minerva Stomatol 2008; 57(3):8194.

\section{Yazışma Adresi}

Erhan GÖRÜKMEZ

Bezmialem Vakıf Üniversitesi, Diş Hekimliği Fakültesi, Ortodonti $A D$, İstanbul/TÜRKİYE TIf: 0(532) 3237023 e-mail: erhan1544@yahoo.com 